\title{
The Value of Weather Event Science for Pending Climate Policy Decisions
}

\author{
JUSTIN DONHAUSER
}

Rotman Institute of Philosophy, The University of Western Ontario, Canada.

ABSTRACT This essay furthers debate about the burgeoning science of Probabilistic Event Attribution (PEA) and its relevance to imminent climate policy decisions. It critically examines Allen Thompson and Friederike Otto's recent arguments concerning the implications of PE $A$ studies for how the United Nations Framework. Convention on Climate Change (UNFCCC) policy framework should be revised during the 2016 'review and decision.' I show that their contention that PEA studies cannot usefully inform decision-making about adaptation policies and strategies is misguided and argue that the current UNFCCC treaty, the "Paris Agreement," supersedes their proposed revision.

There has been a lot of recent debate about whether and how Probabilistic Event Attribution studies (PEAs) can inform climate policy decision-making (see James et al. 2014; Hulme et al. 2011; Hulme 2014; Pall et al. 2011; Stott et al. 2013; Thompson \& Otto 2015). PEAs use super-ensemble climate models and statistical analyses to attribute the occurrence of specific extreme weather events and their impacts (e.g. a drought) to human drivers of climate change (Allen 2003; Stott et al. 2004; Pall et al. 2011; Otto et al. 2012; Bindoff et al. 2013; Stone et al. 2013). PEA researchers make such "attributions" by establishing that a selected climate change driver played a significant role in bringing about a specific extreme weather event. They do this by comparing super-ensemble data models in which the event occurs with possible scenario simulations where selected climate drivers are removed and that weather event does not occur. Through such comparative analyses, they show that an event's likelihood of occurrence would have been substantially lower had the relevant driver not been present (e.g. had U.S. emissions been much lower).

This paper pushes forward discussion of the methods used in PEAs and the relevance of PEAs to imminent and immensely important decisions about the UNFCCC policy framework via critical response to philosopher Allen Thompson and climate scientist Friederike Otto's arguments in a recent paper (2015). One simple reason I critically respond to their paper to advance the 
discussion about PEAs and pending UNFCCC decisions is that it is the most recent major installment in the published literature about PEAs and UNFCCC policy. Their paper is also distinctive in presenting explicit arguments regarding the capabilities and limitations of PEAs for making different sorts of inferences relevant to climate policy and in presenting systematic justification for very specific recommendations for revising the UNFCCC framework. Where numerous authors have drawn conclusions about the potential uses of PEAs and their implications for climate policy, Thompson \& Otto (2015) give these issues a more prolonged and systematic philosophical treatment than one finds elsewhere in the literature.

At the core of Thompson \& Otto's overall argument is the contention that PEA researchers can successfully attribute the occurrence of particular weather events to human drivers of climate change via the methods of PEA but cannot use those methods to make inferences about future events. They say that because of this PEAs are "not directly relevant to adaptation planning" (following Hulme et al. 2011; Hulme 2014) but can directly inform decision-making about losses and damages due to climate change (contra Hulme) (p. 3). Accordingly, their preliminary positive argument is straightforward: because the methods of PEA enable researchers to link extreme events (e.g. "heat waves and subsequent droughts") to losses and damages (e.g. "loss of human life [and] damage to economic productivity"), PEAs provide information that is useful for policy and strategy decision-making concerning losses and damages due to climate change (p. 2; cf. Bhattacharya 2003; Field et al. 2012; Spross 2014).

Thompson \& Otto further argue that, since PEAs cannot inform decisions about adaptation and mitigation but can directly inform decisions about losses and damages, there are "conceptual reasons" to reverse the decision made at COP19 (Warsaw 2013) to provisionally locate policy mechanisms concerning losses and damages (the Warsaw International Mechanism for Loss and Damage [WIM]) within the framework's “adaptation pillar" (the Cancun Adaptation Framework [CAF]) during 
the 2016 'review and decision.' They propose accomplishing this by adding a major framework "pillar" that is "on par with [existing] mitigation, adaptation, technology transfer, and financing" pillars, containing liability-based mechanisms designed to address international justice issues pertaining to losses and damages due to climate change (p. 3). In essence, they submit that while it is at best unclear whether losses and damages can be adequately addressed via adaptive and mitigatory measures, PEAs provide grounds for policy mechanisms that would require parties shown liable (via PEAs) to make reparations to parties whose peoples experience losses or damages. Herein, I show that Thompson \& Otto's conclusions about the limitations of PEAs and about how that the UNFCCC framework should be revised to better address losses and damages that will result from extreme events due to climate change are problematic. I defuse their claim that PEAs "are not directly relevant to" climate change adaptation and mitigation decision-making in two steps (ibid.). I outline ways that PEAs apparently can aid in such decision-making, in $\$ 1$, and then assesses their argument for the claim that PEAs cannot aid in adaptation or mitigation decisionmaking because the methods of PEA are "not designed for" making forward-looking inferences in \$2. I show that they reach this latter conclusion by oversimplifying, and thereby mischaracterizing, the basic reasoning process used in PEAs, and contend that their claim that PEAs are not relevant to adaption and mitigation decision-making is therefore misguided. Although I concur that PEAs can directly inform decisions about addressing losses and damages, and concur that such studies can aid in building the sociopolitical infrastructure needed to appropriately respond to inevitable losses and damages, I then challenge Thompson \& Otto's proposed revisal of the UNFCCC framework in two steps. In $\$ 3$, I show that they do not provide sufficient motivation for developing policy mechanisms for addressing losses and damages that would operate according to a liability-based, "repair," model. Finally, in $\$ 4$, I outline how the 2015 agreement made at COP21 in Paris preserves the provisional outcomes decided at COP19—whereby losses and damages are addressed via adaptive 
and mitigatory measures — and argue that the Paris Agreement opens a better path for making forward progress on addressing losses and damages than it would if it included liability-based mechanisms.

\section{Ways PEAs Can Inform Adaptation Decision-making}

\subsection{PEAs Yield Information that Can Inform Adaptation Decision-making}

PEAs, and the data and ensemble models they use, provide information about changes in the successional patterns, intensity, and frequency of extreme weather events (cf. Peterson et al. 2012, p. 1044). So, it appears that there is a sense in which PEAs can inform adaptation and mitigation decision-making by providing information that enables more reasonable estimations about future weather events and their impacts in particular regions. For example, data models used in PEAs can help show an observable increase in the periodic recurrence of "100 year" floods or droughts in a region due to anthropogenic climate change (Funk 2012; Luo et al. 2015; Peterson et al. 2013; Yu et al. 2014). And such information can be extended to help make inferences about things like possible sociopolitical changes driven by extreme events in particular regions—such as an increase in the likelihood of conflicts driven by agricultural problems resulting from flood or drought conditions (Maystadt \& Ecker 2014). It also stands to reason that the information PEAs provided can augment climate risk models that have been developed specifically for the purpose of informing adaptation decision-making_-such as simulation models designed to assess "economically optimal riskreduction strategies" (McInerney \& Keller 2008; cf. Edwards et al. 2007). Though their position is not overturned by these points, Thompson \& Otto's claim that PEAs are "not directly relevant" to adaption and mitigation decision-making is weakened by the fact that PEAs apparently provide a lot of information that is relevant to forward-looking decision-making.

\subsection{PEAs Can Help Make Better Predictions}


PEA researchers have also demonstrated that even when they cannot link particular anthropogenic drivers (e.g. U.S. emissions) to particular weather event magnitudes, they can still calculate the increased probability of particular events occurring (e.g. heat waves in Russia) given the occurrence of human-driven warming in general using the methods of PEA (Dole et al. 2011; Otto et al. 2012; Pall et al. 2011; Rahmstorf \& Coumou 2011). So, although PEAs may not ever permit one to precisely predict extreme events given the occurrence of certain drivers, it stands to reason that they can nevertheless help better estimate of the likelihood of possible future events. It is true that it is not currently possible to predict the occurrence of extreme weather events with great precision, as there are countlessly many contingent factors that may come into play and therefore a high degree of uncertainty about possible contributory factors to future events (Stott et al. 2013). Even so, the event simulations and statistical analyses used in PEAs can, at least, help make better predictions about possible future extreme events than are possible without them, and it appears that they can therefore aid in forward-looking policy decision-making.

Indeed, as a general point, models that cannot provide precise predictions are often useful for making better decisions than one could without them. An accurate but imprecise weather forecast, like 'there is a high probability of rain,' surely helps one make better decisions about wardrobe and travel plans than she could without it. And although one cannot precisely predict who will or will not get lung cancer from smoking, surely studies that link smoking in general to an increased probability of cancer help particular people make better informed decisions about personal choices and health risks. Accordingly, it appears that PEAs can aid in forward-looking decisionmaking by helping better estimate the likelihood of extreme events and their potential impactscontrary to what Thompson \& Otto suggest.

\subsection{PEAs Can Enable Better Baseline and Threshold Estimation}


Thompson and Otto's claim is further undermined by the fact that the sorts of possible scenario simulations used in PEAs have apparent applications for helping make inferences about variables that are relevant to forward-looking policy and strategy decisions. As just one example, it appears that such simulations have applications for helping estimate baseline and threshold parameters for variables that could be effectively influenced through the implementation of different policies or management strategies. For instance, simulations of possible atmospheric conditions and of how the presence of certain climate drivers influences the likelihood of weather events have heuristic value for estimating baseline and threshold population abundance levels for valuable agricultural and medicinal species. So, it appears that the methods of PEA have potential for aiding in forwardlooking decisions about species protection policies and management strategies (Challinor et al. 2009; Dumas \& Ha-Duong 2013; Gienapp et al. 2013; Kurukulasuriya et al. 2011; Lobell et al. 2013; Seo \& Mendelsohn 2008). It is also reasonable to believe that the sorts of possible event simulations used in PEAs can aid in assessing adaptation policy and strategy options by being used to augment, and examine baselines and thresholds in, other kinds of scenario simulation models. For instance, they could be used to augment existing socioeconomic models such as Shared Socioeconomic Pathways (SSPs) (Rozenberg et al. 2014).

\subsection{PEAs Can Aid in Value Prioritizations and Robustness Analyses}

Further still, it appears that the sorts of simulations PEAs use have heuristic value for formulating policies and strategies to reduce the likelihood that negative impacts of climate change will be experienced (Keller et al. 2008). For example, whether event scenario simulations could aid in determining which of an array of possible adaptation or mitigation actions would most probably advance selected values. One way such simulations could aid in forward-looking decision-making in this way is by being used to help simulate and assign probabilities to multiple possible scenarios in order to rank alternative policies and strategies. Sandra Mitchell outlines the general way in which this sort of 
"probability assigning" and ranking helps formulate more adaptive and robust policies and strategies

with the following example. She writes:

[W] hen the amount of crop yielded by growing corn depends on the weather, then the various outcomes (high yield, low yield) are assigned a probability. The same procedure is applied to outcomes associated with each alternative choice, [...for example,] growing soybeans. Instead of each distinct action that we are considering being associated with a single certain outcome with a single value, we consider [the possible] outcomes of each choice and their associated values consolidated in a measure of expected value. The expected benefit (or in the language of probability theory the "expectation value") of an action is the sum of the possible outcome values weighted by their probabilities. If soybeans are more productive than corn when weather is bad and the probability of the weather being bad is high, then the expected value of growing soybeans may well be higher than the expected value for growing corn, even though one would actually do better growing corn in the less likely situation of the weather being good. (2009, pp. 86-7)

Rather than detailing the formal methods via which simulation models extrapolated from ensemble data might be used to aid in this sort of "adaptive cost-benefit analyses" here, allow me to clarify my general point by glossing just one well-known methodology (Yzer et al. 2014). This is "robust adaptive planning" (RAP)—developed by Bankes, Lempert, \& Popper 2001 and expanded upon a great deal in follow-up works (see Popper et al. 2005; Lempert et al. 2002; Hall et al. 2012). In brief, RAP is a decision-making methodology whereby one seeks the most "robust strategies" (those that maintain and grow options going forward) rather than selecting strategies that maximize utility. Proponents of RAP propose that researchers can determine what are the most robust policy and strategy options by:

- "considering large ensembles of scenarios"

- "using robustness criteria to compare strategy [alternatives]"

- "employing adaptivity to [determine how to maximize strategy] robustness"

- "using the computer as a tool to alternatively suggest breaking scenarios for candidate strategies and clever hedging actions to improve those strategies" (Lempert et al. 2002, p. 438).

Weather event simulations with models extrapolated from ensemble data models, like those used in PEAs, can aid in doing each of these four things. There is therefore yet another sense in 
which PEAs can aid in forward-looking decision-making; by helping researchers better simulate and assign probabilities to possible scenarios and thereby helping formulate and rank forward-looking adaptation and mitigation policy and strategy alternatives.

\section{The Claim that PEAs are "not designed for" Prediction is Misleading}

I have just provided grounds for questioning Thompson \& Otto's claim that PEAs are "not directly relevant to" forward-looking climate policy and strategy decision-making by outlining four ways that PEAs apparently can aid in decision-making about adaptive and mitigatory climate change responses. ${ }^{1}$ To give it a fair shake, I will now reconstruct their argument for their claims regarding the limitations of PEAs (in 2.1), and then show that their argument employs a mischaracterization of the inferential methods used in PEAs (in 2.2) and that their primary contention about the limitations of such studies is therefore misguided (2.3).

\subsection{Thompson \& Otto's Grounds for Claiming that PEA is Irrelevant to Adaptation Decision-making} According to Thompson \& Otto, PEAs give researchers "the ability to attribute the occurrence of a particular extreme event to climate change" but do not enable predictions about future events because they are "about events occurring today or in the recent past" (p. 3). Taking this as given, they conclude that, "[PEAs are] not particularly germane to actions undertaken with the aim of reducing social vulnerability to climate change, and thus not directly relevant to adaptation planning" (ibid.). They then elaborate on this reasoning, saying:

[T] he methods for attributing an increased probability of a particular event of a given magnitude and meteorological state to climate change [...] are designed to offer at least a partial and probabilistic explanation of the cause of that particular token extreme event. The methods of PEA are not designed to predict future occurrences of events of that type. (p. 7, emphasis not added)

From just this, it does not follow that PEAs cannot aid in forward-looking decision-making, since it is entirely possible that the methods employed in PEAs can be useful as such even if they are 
not routinely used that way in currently. Notably, however, Thompson \& Otto do offer a bit more justification for their conclusion. They say that because PEAs concern, "only particular recent or presently occurring extreme events" and the "changed likelihood of the occurrence of events [of that] very same type today, occurring under a specific atmospheric regime," the results of such studies "may not hint at the future, since the circulation regime may well change further" due to factors which are "difficult_-if not impossible—to predict" (ibid.).

So really, they infer that the methods used in PEAs are not useful for making inferences about future weather events because it is impossible to determine which factors will contribute to the background conditions for possible future events. Their conclusion thus rests on the idea that inferences about weather events that have already occurred are grounded in data in a way that forward-looking inferences cannot be. If this is right, the suggestions for how PEAs can aid in adaptation and mitigation decision-making I have outlined above would be problematic — since they all involve making forward-looking inferences from possible scenario simulations. Yet, a closer look at the workings of PEAs shows that my suggestions are not undermined and that Thompson \& Otto's argument relies on a mischaracterization of the workings of PEAs.

\subsection{Thompson \& Otto Mischaracterize How PEAs Work}

It is to be noted that my saying that their argument relies on a mischaracterization of PEAs is not meant to suggest that Thompson and Otto do not understand the technical procedures used in PEAs. My claim is that they oversimplify and thereby underdescribe the inferential process used in such studies - in line with the way that PEA researchers often underdesribe that process when giving summaries of what they do in practice. My point is then that their claim that the methods of PEA are "not designed for" making forward-looking inferences and, so, not relevant to forwardlooking decision-making only makes sense on that underdescribed, and not quite right, understanding of PEAs. 
Thompson \& Otto’s argument glosses over two central aspects of PEAs in particular. First, they underemphasize the integral role that possible scenario simulations (i.e., simulations of fictional or counterfactual events) play in the process of making risk attributions. As I have said, PEA researchers attribute causal contributions of selected climate change drivers (e.g. past emissions) to the increased probability of a weather event occurring through comparative analyses of simulations with ensemble data models and counterfactual scenario simulations with models extrapolated from such data models. Otto herself explains this quite clearly in a recent entry on the climate science and policy website The Carbon Brief, saying:

Because we don't get a lot of observations of the most extreme events, almost by definition, [risk attributions...] are based on large numbers of climate model experiments, called "ensembles". [PEAs] compare how often a particular extreme weather event occurs in model experiments representing the 'world as it is' (with human influence on climate) with how often it occurs in experiments representing the 'world that might have been', where the estimated impact of human influence on climate is removed. ${ }^{2}$

Otto's operational outline of how PEAs work in this entry is straightforward, correct, and in line with how the basic methods used in PEAs are typically understood. And in perhaps the most widely cited PEA study, the authors describe the workings of PEAs in the same way, saying: "[in PEAs, t]he probability of a particular event happening in an ensemble of model simulations representing current conditions is compared with a parallel ensemble of model simulations representing an alternative world that might have occurred had the particular driver been absent" (Stott et al 2013, p. 315). Thompson \& Otto do not explain this in their recent paper, and their overall argument underplays the central role counterfactual scenario simulations play in the reasoning process used to justify risk attributions.

What's more problematic is that they also underdescribe how PEAs work by failing to note that what is attributed via the methods of PEA is not the contribution that a selected climate change driver actually made to the realization of a weather event, but the contribution some selected driver 
could have possibly made to the probability that that event might occur. In fact, they explicitly claim that PEAs can provide "a partial and probabilistic explanation of the cause of" particular, token, eventsand make more general claims that ensemble models accurately 'represent the world as it is.' But, this is not right.

It is true that PEA researchers make claims about which factors play substantive causal roles in bringing about particular events, and true that researchers make assumptions about the causal structure of nature. However, the theoretical and mathematical machinery used in PEAs deals with abstract entities and probabilities and is itself blind to, or theory-neutral regarding, causality and matters of metaphysics (cf. Pearl 2000). ${ }^{3}$ Accordingly, the more correct thing to say is simply that PEA researchers make risk attributions on the basis of comparisons between data-driven simulations and simulations of counterfactual events, and therefore make inferences about actual events on the basis of simulated events in counterfactual "model worlds" (Hannart et al. 2015). In this process, the calculation of the fractional increase in the risk of a selected extreme event occurring is based on simulations of counterfactual events. Thompson \& Otto's argument is therefore problematic because they claim that the methods used in PEAs provide causal explanations, when they actually provide information about 'the probability of possible events occurring, or not occurring, within models' that researchers then use to make inferences. ${ }^{4}$

\subsection{A More Optimistic View of the Methods of PEA}

To be clear, I am not spotlighting the role of counterfactual scenario simulations in PEAs to suggest that these studies are somehow problematic. I do so to illuminate the fact that the sort of evidence and inferential process used to justify risk attributions in PEAs is essentially the same sort of evidence and process that one would use to justify forward-looking inferences with the sorts of models used in PEAs. The evidence used to justify risk attributions comes from counterfactual scenario simulations with models extrapolated from ensemble data models and the process is one of 
making inferences about weather events on the basis of such simulations. Hence, if one believes that the methods of PEA are sound and therefore useful for decision-making about losses and harms (as we should), one should also believe that they can be useful for forward-looking decisionmaking. ${ }^{5}$

This is because in either sort of effort researchers would use models extrapolated from data models, and change selected variables and parameter values in those models to simulate some counterfactual way(s) the world could be, to help make inferences. In either case ("hindcasting" or "forecasting"), one makes inferences about weather events on the basis of information from simulations of counterfactual scenarios (cf. Stott et al. 2013). So, risk attributions are not grounded data in a way that forward-looking determinations cannot be, as such inferences are made on the basis of simulations of counterfactual scenarios just as forward-looking inferences must be.

I must admit that Thompson \& Otto are right that one cannot calculate the fractional increase in the risk of a possible future event in the same way PEA researchers do when making risk attributions, because there is not, and cannot be, data on future events to enable this calculation. Yet, this hardly warrants their conclusion that the methods used in PEAs are not relevant to forward-looking decision-making. It just means that one step in the specific technical process used to make risk attributions cannot be used for making forward-looking inferences. ${ }^{6}$ Even so, an array of different scenario analyses that can aid in forward-looking decision-making can be done with the sorts of models and methods used in PEAs. So, although it is true that the specific procedure for estimating the fractional increase in the risk of an event in PEAs is not designed for making predictions, Thompson \& Otto's more general claim that the methods used in PEAs are not of use for adaptation and mitigation decision-making does not wash. To the contrary, a careful look at the workings of PEAs shows that the model-based reasoning processes employed in these studies does 
not differ from that employed in forward-looking model-based reasoning in any essential way, and shows that Thompson \& Otto's argument is problematic.

\section{The Proposed UNFCCC Framework Revision Lacks Motivation}

Although their claims about the relevance of PEAs to adaptation and mitigation decision-making are problematic, Thompson \& Otto rightly point out that attributions of extreme weather events to climate change by the methods of PEA "are ethically significant and have normative implications for pending policy decisions" (p. 3). And they succeed in establishing that PEAs would be useful for decision-making about reparations for loses and damages even if they weren't useful for adaptation and mitigation decision-making. They also rightly point out that PEAs provide information that can aid in developing "long-term international relations" and institutional infrastructure needed to respond appropriately to international and intergenerational justice issues due to anthropogenic climate change (ibid.). Yet, their proposal for revising the UNFCCC policy framework is also problematic.

Recall, Thompson \& Otto recommend reversing the decision made at COP19 to address concerns about losses and damages via mitigation and adaptation strategies. Specifically, proposing the development of a new pillar, "on par with [existing] mitigation, adaptation, technology transfer, and financing" pillars, that would include mechanisms for addressing losses and damages that operate according to a "repair model"-whereby nations who have made more significant contributions to raising the probability of extreme weather events are held liable for experienced losses or damages. Thompson \& Otto offer three "conceptual reasons" to motivate this proposal, which I will now show do not suffice to do so.

Following their order of presentation, their first "conceptual reasons to support the development of a mechanism for loss and damage into an independent pillar" is that losses and 
damages are not addressed under mechanisms to address adaptation and mitigation concerns by definition in the UNFCCC framework (p. 3). In the UNFCCC framework, mitigation mechanisms 'pertain to taking actions to reduce the magnitude of climate change by reducing the efficacy of climate change drivers'. By contrast, adaptation mechanisms 'pertain to taking strategies that reduce harms caused by extreme events and reduce risks of loses and harms.' Hence, Thompson \& Otto are right that: "loss and damage are distinct from adaptation and mitigation, in the sense that there may well be residual loss and damages that cannot be successfully addressed" by mitigation or adaptation efforts (p. 6). This is because adaptation and mitigation mechanisms are forward-looking and not designed to provide guidance in developing the sorts of backward-looking policies and strategies needed to address residual losses and damages.

Of course, this is a good reason to further develop policy mechanisms for addressing losses and damages, and it is clear that liability-based mechanisms would serve as a means of addressing residual losses and damages. However, this is not a sufficient reason to develop a separate pillar of the framework containing liability-based compensation mechanisms. This is because, pending further justification, it is unclear that doing so would be beneficial. It is also entirely possible that there are adaptation and mitigation measures that would provide better means of addressing residual losses than liability-based measures.

Thompson \& Otto’s second “conceptual reason” for developing a liability-based losses and damages pillar of the UNFCCC framework also does not suffice to motivate doing so. As they explain their second justification, "the possibility of residual loss and damages supports the position that [the] WIM should not be located in CAF" (ibid.). To a certain extent, this consideration is already implicit in their first, and essentially reinforces their claim that their proposal should go through because residual losses and damages are by definition neglected by adaptation and mitigation mechanisms. However, it is an independent justification because their claim here is that 
the mere possibility of residual losses and damages itself warrants developing an independent pillar containing liability-based compensation mechanisms. Yet again, pending further justification, this consideration does not support developing such mechanisms, since it is at best unclear that this would offer any advantages and possible that there are viable adaptation and mitigation measures for addressing losses and damages. Hence, while the possibility, and even actuality, of residual losses and damages certainly warrants the conclusion that enhanced measures for addressing losses and damages should exist, it does not justify developing independent liability-based policy mechanisms.

Thompson \& Otto's final justification for their proposal is tied to their claim that PEAs can offer 'at least a partial and probabilistic explanation of the cause of particular extreme events' but cannot provide information relevant to forward-looking decision-making. They contend that there should be a major pillar containing liability-based compensation mechanisms for addressing losses and damages because PEAs serve as a science that can aid in operationalizing such mechanisms but cannot aid in operationalizing mitigation and adaptation measures. I have shown already that this conclusion is misguided (in $\$ 2$ ). Yet, even if it weren't, this reason also does not suffice to motivate their proposal.

To the contrary, in general, giving the development of preemptive adaptation and mitigation measures priority over developing repair-based responses to losses and damages seems the more practical route, even when the capacity to address losses and damages via reparative measures is more highly developed. To illustrate this, suppose that one was aware of measures that would enable her to sufficiently cope with losses due to a home robbery (e.g. anxiety drugs and law enforcement), but was not aware of measures to adequately preempt or avoid potential future robberies (e.g. prediction abilities and security measures). In this case, it does not seem that one's effort to develop means of addressing losses due to robbery should be "on par" with her effort to develop ways of mitigating potential future losses and finding ways to adapt so as to avoid 
experiencing such losses - even if her capabilities for operationalizing measures to mitigate and avoid losses were lacking. Analogously, the claim that policy mechanisms for addressing losses and damages should be on par with those for addressing adaptation and mitigations concerns lacks intuitive appeal. Even if it is true that we are better equipped to operationalize policies and strategies designed to address losses and damages through liability-based compensation measures (which is contentious in the least), it does not follow that we should not still put far greater effort into further developing mitigatory and adaptive measures.

\section{The Paris Agreement and the Path Forward on Loss and Damage}

Since the publication of Thompson \& Otto's 2015 paper, negotiations at COP21 in Paris produced an agreement that includes substantive revisions. Most notably, the Paris Agreement does include a major section, or “independent pillar," containing recommendations for further developing measures for addressing losses and damages. However, those recommendations do not suggest developing liability-based compensation measures to address losses and damages but suggest taking primarily adaptive measures, and even include an explicit “no liability” clause (ibid. \52).

In fact, the Paris Agreement preserves the provisional commitment to addressing losses and damages via mitigation and adaptation measures decided at COP19 by calling for, "continuation of the Warsaw International Mechanism for Loss and Damage associated with Climate Change Impacts, following the review in 2016” (\$48). The Losses and Damages section of the agreement also includes a substantive request of the Executive Committee of the Warsaw International Mechanism to take steps to develop infrastructure to support risk insurance, and risk-transfer and pooling protocol, to address losses and damages before the 2016 review. Specifically, it states that the committee is to establish: "a clearinghouse for risk transfer that serves as a repository for information on insurance and risk transfer, in order to facilitate the efforts of Parties to develop and implement comprehensive risk management strategies" (\$49).” Finally, the no liability clause in the 
Losses and Damages section plainly states that, "the Agreement does not involve or provide a basis for any liability or compensation” (\$52).

Those who share Thompson \& Otto's desire to see liability-based measures for addressing losses and damages realized may be inclined to decry the outcome of the Paris negations—on the grounds that it is morally inadequate. Yet, even though it may be morally inadequate, I submit that the Paris Agreement still opens a better path for making substantive forward progress on addressing losses and damages than it would if it included liability-based mechanisms. Accordingly, I propose that rather than contesting the outcome in Paris, the most fruitful way forward will be to concentrate on developing proposals and possible implementation strategies for "comprehensive risk management strategies" and hashing out ways that the risk insurance and risk-pooling suggested in the agreement could be operationalized.

An obvious practical reason to work with the Paris Agreement is simply that it is the agreement to which parties to the convention have already agreed. What's more, the recommendations contained in the Losses and Damages section are not just passable, but present a sophisticated way of dealing with the fact that many UNFCCC parties will likely never accept liability-based compensation measures — and could forever contend that it is not possible to establish liability for experienced losses and damages beyond any doubt. The recommendations in the Paris Agreement are also consistent with UNFCCC parties' standing commitment to the idea that sufficiently addressing justice issues due to losses and damages will require massive international, broadly sociopolitical, adaptation efforts to put in place the institutional architecture needed to do so. A commitment is perhaps most clearly expressed within the WIM, wherein the working group advises further development of the Durban Platform:

[Through e]nhanced action and international cooperation on adaptation [that] is urgently required to enable and support the implementation of adaptation actions aimed at reducing vulnerability and building resilience in developing country Parties, 
taking into account the urgent and immediate needs of those developing countries that are particularly vulnerable. [As well as through recognition of] the importance of regional and international cooperation with a view to promoting the establishment of alliances to support the implementation of actions aimed at reducing vulnerability and building resilience to the adverse effects of climate change. (UNFCCC 2013b, p. 3)

Finally, there is also a simple economic rationale for addressing losses and damages primarily via adaptation and mitigation measures that is presented in numerous places in the UNFCCC literature. For instance, in a technical report on non-economic losses (UNFCCC2013a) the working group explains that:

There is a link between the magnitude of adaptation cost, mitigation cost and loss and damage. Increasing the mitigation effort (higher mitigation costs) would reduce loss and damage and make adaptation cheaper. For example, greater mitigation should result in a smaller increase in sea levels and so less protection from sea level rise will be required. Increasing the amount of adaptation (higher adaptation cost) will also reduce loss and damage. (p. 4)

Those still wanting liability-based measures for addressing losses and damages despite these practical justifications for favoring adaptive and mitigatory measures should also consider that the measures outlined in the Paris Agreement will facilitate cooperation and the development of political infrastructure between "developing" and "developed" countries necessary to implement any compensation-based means of addressing losses and damages. As Thompson \& Otto say:

$[T]$ he degree of international cooperation requisite to build institutions appropriate to address the global and intergenerational environmental problems will depend upon achieving political reconciliation between the developing countries (who will suffer first, suffer most, and bear least historic responsibility) and the developed countries (who will likely suffer less in the short term but bear most historic responsibility)[.] (p. 11)

In view of this, it should come as a considerable consolation to those wanting liability-based measures that the risk-pooling measures outlined in the Paris Agreement have the potential to serve as a means of making significant progress toward achieving the requisite sort of "political reconciliation.” Indeed, the outlined risk-pooling measures arguably provide a better basis for 
achieving cross-national reconciliations and facilitating morally acceptable responses to inevitable losses and damages than setting up provisions for liability-based restitutions. This is because achieving political reconciliation and operationalizing adequate responses will require institutional adaptations and the development of international arrangements whereby probable climate change "victims" are provided options for maintaining a reasonable quality of life by parties who have driven climate change. And, because they outline a judicious way to initiate such adaptions and agreements, the recommendations in the Paris Agreement are apparently superior to possible liability-based compensation measures. In the very least, revising the recommendations on losses and damages in the Paris agreement to follow the "repair" model of justice Thompson \& Otto, and many others, endorse would not offer any obvious advantages (pp. 11-12).

Acceptance of the fact that it is no longer possible to respond to climate change without dealing with losses and damages is reflected throughout the policy track that lead to the development of the WIM (UNFCCC 2013b). Yet, accepting that there will be unavoidable losses and damages due to climate change does not require one to accept that focusing on efforts to make "repairs," post loss and damage, is the best path forward. ${ }^{7}$ The Paris Agreement adheres to what Daniel Bodansky (2012) has called a "facilitative model" of international justice, which emphasizes developing institutional architecture and protocol for preempting and minimizing the magnitude of experiences of losses and damages. Unlike a repair model, this model does not accept experienced losses and damages as precondition for reconciliation, but emphasizes initiating institutional adaptations whereby developed countries help people in developing countries avoid and cope with the impacts of extreme events by providing them options for doing so. In accordance with this forward-looking model, the Paris Agreement outlines a path for making progress on addressing losses and damages via forward-looking adaptation and mitigation measures that I have argued offer practical and political advantages over backward-looking liability-based measures and that we should 
therefore embrace. I submit, moreover, that the outcomes of the Paris negotiations provide grounds for much important work on how the suggested risk-insurance and risk-pooling could be operationalized and what reasonable "comprehensive risk management strategies" might look like. The Paris Agreement thereby also provides grounds for work exploring how PEAs can aid in devising risk-pooling protocol and risk management strategies.

\section{Conclusion}

Thompson \& Otto (2015) highlight the importance of exploring the relevance of PEAs to pending UNFCCC decisions. I have augmented their positive account of how PEAs can aid in policy and strategy decision-making by showing that, in addition to their potential to directly inform backwardlooking decisions about responding to experienced losses and damages, PEAs can play valuable heuristic roles in decision-making about forward-looking adaptive and mitigatory responses. I have argued, moreover, that their proposal to address unavoidable losses and damages by adding liabilitybased compensation mechanisms to the UNFCCC treaty has been outstripped by the practically and politically advantageous adaptive and mitigatory measures outlined in the Paris Agreement. Finally, I have urged that the Paris Agreement provides a basis for making substantive progress on addressing losses and damages, and therefore opens avenues for crucially important work examining how riskpooling measures and risk management strategies can be best operationalized and avenues for further examination of how PEAs can aid in pending policy and strategy decisions.

\section{Acknowledgements}

I am grateful to participants in the 2015 Workshop on Ethics and Adaptation in Buffalo, NY for drawing my attention to various aspects of the issues discussed in this work. Special thanks to Idil Boran for reminding me about Bodansky's notion of 'facilitative institutions.' Most importantly, I must thank Allen Thompson, Frank Jankunis, and an anonymous reviewer for helpful comments on earlier versions of this work. 


\begin{abstract}
1 There are many heuristic uses of models in general that I will not discuss here; Donhauser 2014 and Wimsatt 2007 each discuss some of those uses.

2 www.carbonbrief.org/blog/2014/10/attributing-extreme-weather-to-climate-change-in-realtime/

3 Thompson \& Otto address this somewhat by stipulating that PEA researchers attribute "probabilistic causes." However, this is not to acknowledge that causal attributions are speculative hypotheses made by researchers and are not equivalent to the attribution of some simulated climate change driver within a model as a "probability raiser" within that model scenario. What's more, the notion of 'probabilistic cause' is deeply problematic for reasons I will not rehearse here; see Hitchcock 2004, Menzies 1989, Salmon 1980 for discussion.

4 There are many, especially thorny, issues regarding the nature of causation and causal attributions that would significantly complicate this discussion, and that I will here assume can be met for reasons of editorial economy. For readers who wish to pursue those issues and their bearing on evaluating PEAs, the relevant concerns are often addressed as the 'problem of counterfactual conditionals' in contemporary logic and philosophy of science. This problem was first discussed in depth by Chisholm (1946) and Goodman (1947) in the relevant literature, and there is a rich literature considering the nuances of the problem; Collins et al (2004) provide an illuminating overview of the issue and its history. Schaffer (2001) provides a helpful discussion of the difference between causes and 'probability-raisers.'

${ }^{5}$ Confidence in risk attributions must be founded upon a confidence in the theoretical machinery and systematic logical processes used to arrive at those inferences in PEAs, because founding it upon the fact that such attributions are consistent with the co-occurrence of selected drivers and weather events after the fact (i.e. post hoc ergo propter hoc) is to engage an egregious confirmation bias.

${ }^{6} \mathrm{I}$ am not denying that there are differences between the model-based reasoning processes and uses of models in doing risk attribution analyses and doing predictive analyses. These include using different mathematical tricks to minimize simulation error and other tricks to minimize prediction error, and also include the fact that that forward-looking simulations cannot be evaluated on the basis of their accordance with data-models.

${ }^{7}$ Indeed, one might reasonably contend that building a tolerance of losses and damages into the UNFCCC agreement as a default attitude would be morally unacceptable.
\end{abstract}

\title{
References
}

Allen, Myles. (2003). Liability for climate change. Nature, 421(6926), 891-892.

Bankes, Steven C, Lempert, Robert J, \& Popper, Steven W. (2001). Computer-Assisted Reasoning. Computing in Science \& Engineering, 3(2), 71-77.

Bhattacharya, Shaoni. (2003). European heatwave caused 35,000 deaths. New Scientist, 10(10), 03.

Bindoff, Nathaniel L, Stott, Peter A, AchutaRao, M, Allen, Myles R, Gillett, N, Gutzler, David, ... Jain, Suman. (2013). Detection and attribution of climate change: from global to regional. In T. F. Stocker, et al. (Ed.), Climate Change 2013: The Physical Science Basis. Contribution of Working Group I to the Fifth Assessment Report of the Intergovernmental Panel on Climate Change

Bodansky, Daniel. (2012). The Durban Platform Negotiations. Harvard Project on Climate Agreements Viewpoint. From: http://belfercenter.ksg.harvard.edu/publication/22196/durban_platform_negotiations.html

Challinor, Andrew Juan, Wheeler, Tim, Hemming, Debbie, \& Upadhyaya, HD. (2009). Ensemble yield simulations: crop and climate uncertainties, sensitivity to temperature and genotypic adaptation to climate change. Climate Research, 38(2), 117-127.

Chisholm, Roderick M. (1946). The contrary-to-fact conditional. Mind, 289-307.

Collins, John, Hall, Ned, \& Paul, LA. (2004). Counterfactuals and causation: History, problems, and prospects. In J. Collins, N. Hall \& L. Paul (Eds.), Causation and Counterfactuals: MIT Press.

Dole, Randall, Hoerling, Martin, Perlwitz, Judith, Eischeid, Jon, Pegion, Philip, Zhang, Tao, . . Murray, Donald. (2011). Was there a basis for anticipating the 2010 Russian heat wave? Geophysical Research Letters, $38(6)$. 
Donhauser, J. (2014). “On How Theoretical Analyses in Ecology can Enable Environmental ProblemSolving." Ethics \& the Environment, 19(2): 91-116.

Dumas, Patrice, \& Ha-Duong, Minh. (2013). Optimal growth with adaptation to climate change. Climatic change, 117(4), 691-710.

Edwards, Tamsin L, Crucifix, Michel, \& Harrison, Sandy P. (2007). Using the past to constrain the future: how the palaeorecord can improve estimates of global warming. Progress in Physical Geography, 31(5), 481-500.

Field, Christopher, \& Barros, Vicente (Eds.). (2014). Climate Change 2014: Impacts, Adaptation, and V ulnerability. Part A: Global and Sectoral Aspects. Contribution of Working Group II to the Fifth Assessment Report of the Intergovernmental Panel on Climate Change (Vol. 1): Cambridge University Press.

Funk, Chris. (2012). Exceptional warming in the western Pacific-Indian Ocean warm pool has contributed to more frequent droughts in eastern Africa. Explaining extreme events of 2011 from a climate perspective: Bulletin of the American Meteorological Society, 93, 1049-1051.

Gienapp, Phillip, Lof, Marjolein, Reed, Thomas E, McNamara, John, Verhulst, Simon, \& Visser, Marcel E. (2013). Predicting demographically sustainable rates of adaptation: can great tit breeding time keep pace with climate change? Philosophical Transactions of the Royal Society B: Biological Sciences, 368(1610), 20120289.

Hall, Jim W., Lempert, Robert J., Keller, Klaus, Hackbarth, Andrew, Mijere, Christophe, \& McInerney, David J. (2012). Robust Climate Policies Under Uncertainty: A Comparison of Robust Decision Making and Info-Gap Methods. Risk Analysis, 32(10), 1657-1672. doi: 10.1111/j.1539-6924.2012.01802.x

Hannart, A, Pearl, J, Otto, FEL, Naveau, P, \& Ghil, M. (2015). Causal counterfactual theory for the attribution of weather and climate-related events. Bulletin of the American Meteorological Society(2015).

Hitchcock, C. (2004). Do All and Only Causes Raise the Probabilities of Effects? In J. Collins, E. J. Hall \& L. A. Paul (Eds.), Causation and Counterfactuals: MIT Press.

Hulme, Mike. (2014). Attributing weather extremes to 'climate change'A review. Progress in Physical Geography, 0309133314538644.

Hulme, Mike, O’Neill, Saffron J, \& Dessai, Suraje. (2011). Is weather event attribution necessary for adaptation funding. Science, 334(6057), 764-765.

James, Rachel, Otto, Friederike, Parker, Hannah, Boyd, Emily, Cornforth, Rosalind, Mitchell, Daniel, \& Allen, Myles. (2014). Characterizing loss and damage from climate change. Nature Climate Change, 4(11), 938-939.

Keller, Klaus, Yohe, Gary, \& Schlesinger, Michael. (2008). Managing the risks of climate thresholds: uncertainties and information needs. Climatic Change, 91(1), 5-10.

Kurukulasuriya, Pradeep, Kala, Namrata, \& Mendelsohn, Robert. (2011). Adaptation and climate change impacts: a structural Ricardian model of irrigation and farm income in Africa. Climate Change Economics, 2(02), 149-174.

Lempert, Robert, Popper, Steven, \& Bankes, Steven. (2002). Confronting surprise. Social Science Computer Review, 20(4), 420-440.

Lobell, David B, Baldos, Uris Lantz C, \& Hertel, Thomas W. (2013). Climate adaptation as mitigation: the case of agricultural investments. Environmental Research Letters, 8(1), 015012.

Luo, Pingping, He, Bin, Takara, Kaoru, Xiong, Yin E, Nover, Daniel, Duan, Weili, \& Fukushi, Kensuke. (2015). Historical assessment of Chinese and Japanese flood management policies and implications for managing future floods. Environmental Science \& Policy, 48, 265-277.

Maystadt, Jean-François, \& Ecker, Olivier. (2014). Extreme weather and civil war: does drought fuel conflict 
in Somalia through livestock price shocks? American Journal of Agricultural Economics, 96(4), 1157-1182.

McInerney, David, \& Keller, Klaus. (2008). Economically optimal risk reduction strategies in the face of uncertain climate thresholds. Climatic Change, 91(1-2), 29-41.

Menzies, Peter. (1989). Probabilistic causation and causal processes: A critique of Lewis. Philosophy of Science, 642-663.

Mitchell, S. (2009). Unsimple Truths: Science, Complexity, and Policy: University Of Chicago Press.

Nelson, Goodman. (1947). The Problem of Counterfactual Conditionals. The Journal of Philosophy, 44(5), 113128. doi: $10.2307 / 2019988$

Otto, FEL, Massey, N, Oldenborgh, GJ, Jones, RG, \& Allen, MR. (2012). Reconciling two approaches to attribution of the 2010 Russian heat wave. Geophysical Research Letters, 39(4).

Pall, Pardeep, Aina, Tolu, Stone, Dáithí A, Stott, Peter A, Nozawa, Toru, Hilberts, Arno GJ, . . Allen, Myles R. (2011). Anthropogenic greenhouse gas contribution to flood risk in England and Wales in autumn 2000. Nature, 470(7334), 382-385.

Pearl, J. (2000). Causality: models, reasoning, and inference: Cambridge University Press.

Peterson, Thomas C, Heim Jr, Richard R, Hirsch, Robert, Kaiser, Dale P, Brooks, Harold, Diffenbaugh, Noah S, . . Karl, Thomas R. (2013). Monitoring and understanding changes in heat waves, cold waves, floods, and droughts in the U.S. Bulletin of the American Meteorological Society, 94(6), 821-834.

Peterson, Thomas C, Stott, Peter A, \& Herring, Stephanie. (2012). Explaining extreme events of 2011 from a climate perspective. Bulletin of the American Meteorological Society, 93(7), 1041-1067.

Popper, Steven W, Lempert, Robert J, \& Bankes, Steven C. (2005). Shaping the future. Scientific American, 292(4), 66-71.

Rahmstorf, Stefan, \& Coumou, Dim. (2011). Increase of extreme events in a warming world. Proceedings of the National Academy of Sciences.

Rozenberg, Julie, Guivarch, Céline, Lempert, Robert, \& Hallegatte, Stéphane. (2014). Building SSPs for climate policy analysis: a scenario elicitation methodology to map the space of possible future challenges to mitigation and adaptation. Climatic change, 122(3), 509-522.

Salmon, WC. (1980). Probabilistic Causality. Pacific Philosophical Quarterly, 61(1-2), 50-74.

Schaffer, J. (2001). “Causes as probability raisers of processes.” Journal of Philosophy, 98(2), 75-92.

Seo, S Niggol, \& Mendelsohn, Robert. (2008). An analysis of crop choice: Adapting to climate change in South American farms. Ecological Economics, 67(1), 109-116.

Spross, J. (2014, July 9 2014). Heat Waves Could Triple Premature Deaths In Britain by 2050. From: http://thinkprogress.org/climate/2014/07/09/3458126/britain-heat-hospitals/

Stone, Dáithí, Auffhammer, Maximilian, Carey, Mark, Hansen, Gerrit, Huggel, Christian, Cramer, Wolfgang, . .. Tibig, Lourdes. (2013). The challenge to detect and attribute effects of climate change on human and natural systems. Climatic Change, 121(2), 381-395.

Stott, Peter A, Allen, Myles, Christidis, Nikolaos, Dole, Randall M, Hoerling, Martin, Huntingford, Chris, ... Stone, Dáithí. (2013). Attribution of weather and climate-related events Climate Science for Serving Society (pp. 307-337): Springer.

Stott, Peter A, Stone, Dáithí A, \& Allen, Myles R. (2004). Human contribution to the European heatwave of 2003. Nature, 432(7017), 610-614.

Thompson, A., \& Otto, F. E. (2015). "Ethical and normative implications of weather event attribution for policy discussions concerning loss and damage." Climatic Change, 1-13. 
UNFCCC. (2013a). Non-economic Losses in the Context of the Work Programme on Loss and Damage. From: http://unfccc.int/resource/docs/2013/tp/02.pdf

UNFCCC. (2013b). Warsaw international mechanism for loss and damage associated with climate change impacts. From: http://unfccc.int/resource/docs/2013/cop19/eng/10a01.pdf

UNFCCC. (2015). Adoption of the Paris Agreement. From: http://unfccc.int/resource/docs/2015/cop21/eng/109r01.pdf

Wimsatt, W. C. (2007). Re-Engineering Philosophy for Limited Beings, Harvard University Press.

Yu, Meixiu, Li, Qiongfang, Hayes, Michael J, Svoboda, Mark D, \& Heim, Richard R. (2014). Are droughts becoming more frequent or severe in China based on the standardized precipitation evapotranspiration index: 1951-2010? International Journal of Climatology, 34(3), 545-558.

Yzer, Jerrel R, Walker, Warren E, Marchau, VAWJ, \& Kwakkel, Jan H. (2014). Dynamic adaptive policies: A way to improve the cost-benefit performance of megaprojects. Environ. Plann. B, 2071-1050. 